\title{
Efficacy of prolonged regimes of oxytetracycline in the treatment of nongonococcal urethritis
}

\author{
JOSHY JOHN* \\ St. Bartholomew's Hospital, London
}

For some years, in many British clinics, the treatment of choice for nongonococcal urethritis has been oxytetracyline, the dosage most frequently employed being $250 \mathrm{mg}$. four times a day for 5 days. The object of this investigation was to assess the value of larger or more prolonged dosage.

\section{Material and methods}

The study was conducted in the Venereal Diseases Department, St. Bartholomew's Hospital, London. The diagnosis of nongonococcal urethritis was based on the presence of a sexually acquired urethral discharge, containing abundant polymorphonuclear leucocytes, shown not to be due to gonorrhoea by negative findings in Gramstained smears and by negative results to cultures. Cases in which the discharge was associated with Candida, or with Trichomonas vaginalis demonstrated in wet smears, were excluded. Patients who presented with insufficient urethral discharge for diagnostic purposes were reexamined by the early-morning smear procedure. Cases were unselected and after diagnosis were allocated to one of three treatment groups:

Group A Oxytetracycline $500 \mathrm{mg}$. three times a day for 5 days

Group B Oxytetracycline $250 \mathrm{mg}$. four times a day for 21 days

Group C Oxytetracycline $500 \mathrm{mg}$. four times a day for 10 days.

Received for publication February 4, 1971

$\star$ Present address: St Mary's Hospital, Paddington, London, W.2

Patients were asked to return for follow-up as follows:

Group $A$ After 1, 2, and 4 weeks, and finally at 3 months from the commencement of treatment.

Group B Weekly during the first 4 weeks, fortnightly for the next 4 weeks, and finally at the end of the third month.

Group $C$ After 1 week, then fortnightly for 4 weeks, then 1 month later, and finally at the end of the third month.

The criteria for cure were the cessation of symptoms, the absence of urethral discharge, and the passage of macroscopically clear urine in the two-glass test. Patients in whom there was failure of treatment were re-treated with a single injection of $1 \mathrm{~g}$. streptomycin together with a 5-day course of a sulphonamide drug.

\section{Results of treatment (Table)}

Needless to say, a number of patients defaulted shortly after receiving treatment, and not all of those who continued their follow-up attended on the days requested. The principal assessment was made at the attendance nearest to the 4th week after the commencement of treatment. The total of those available for assessment at this time was 501 patients:

Group A-132; Group B-200; Group C-169.

In Group $A$, recurrence of nongonococcal urethritis at or about the 4th week was recorded in $\mathbf{7 5}$ of 132 patients followed, a cure rate of 57 per cent. During the succeeding month, recurrence was

TABLE Results of treatment with oxytetracyline

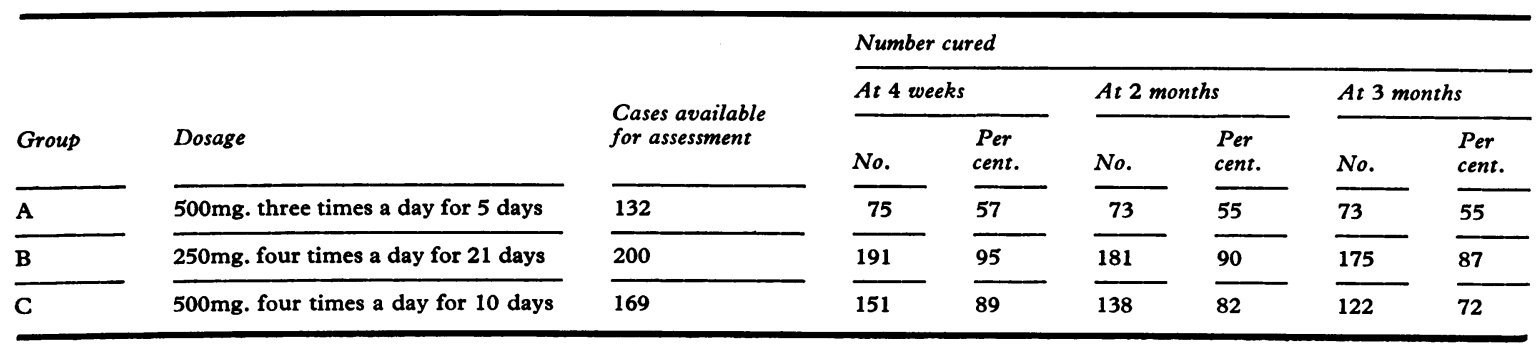


diagnosed in a further two cases but none occurred in the 3rd month. Accordingly, the initial cure rate was 57 per cent. and the final cure rate 55 per cent.

In Group B, 191 of 200 patients followed (95 per cent.) were judged to be cured at 1 month. In the succeeding 2 nd and 3 rd months there were ten and six recurrences respectively, giving cure rates at the 2nd and 3rd months of 90 and 87 per cent.

In Group C, 151 of 169 patients followed (89 per cent.) were considered to be cured after one month. Cure rates at the end of the 2 nd and 3 rd months were 82 and 72 per cent. respectively.

\section{Discussion}

The efficacy of the tetracyclines in the treatment of non-gonococcal urethritis has been under fairly frequent scrutiny for nearly 20 years and at the very least thirty published trials have contributed to the 'common knowledge' that cure will result in about 70 to 80 per cent. of cases treated with a 5- or 7-day course given in a dosage of $250 \mathrm{mg}$. every 6 hours. Nevertheless this 'common knowledge' is an assumption which conceals wide variations in reported cure rates deriving from trials of greatly different method and validity. Certainly the effect of tetracycline is genuine: this was best proved by Holmes, Johnson, and Floyd (1967), who compared two tetracycline regimes with a placebo in a cross-over trial which involved patients under close scrutiny in an aircraft carrier with whom the problem of relapse versus re-infection was as near as possible eliminated. But of course of considerable importance in judging results is the time of the principal assessment for cure. Not only does the problem of re-infection increase with time, but so also does the spontaneous cure rate. It has been shown that early 'cure' can be obtained in about 20 to 25 per cent. of cases using no treatment or a placebo (Doyle, Gill, and Laird, 1957; Csonka, 1959), but late cure may result in up to 70 per cent. of placebo-treated cases observed for between 1 and 3 months (Holmes and others, 1967). This matter was exemplified in the controlled trial recently published by Fowler (1970): cure rates yielded by a 4-day course of tetracycline or a placebo after 14 days were 72 and 37 per cent. respectively, but by the end of 3 months it appeared that tetracycline had benefited only 10 per cent. more patients than the number considered to be 'cured' by the placebo treatment. The word 'cure' used in respect of placebo-treated cases does not, of course, take into account the prolonged symptoms and probably higher incidence of complications.

In the present trial the principal assessment was made at about the fourth week after the beginning of treatment and there was no attempt to distinguish treatment failure from re-infection. The 5-day $\stackrel{\vec{F}}{\vec{S}}$ course of treatment appeared to yield a smaller $\bar{Q}$ 'early' cure rate (57 per cent.) than is usual, possibly because the time of assessment was later than the $\frac{\bar{\omega}}{\vec{D}}$ usual 2 weeks; this is possibly borne out by the find- $\stackrel{\mathbb{Q}}{\Omega}$ ings at 3 months which were virtually the same, namely 55 per cent.

Considering patients receiving the 21-day course of tetracycline (Group B), it might have been argued $\vec{\omega}$ that the superior early cure rate of 95.5 per cent. at $\stackrel{\omega}{\sigma}$ one month was due to early assessment after the $\stackrel{\text { ? }}{=}$ completion of treatment and to the effect of continued therapy protecting against early re-infection. is If the latter were the case, it seems to be a valid use $\mathcal{O}$ of treatment, but the cure rate at 3 months $(87.5 \mathrm{O}$ per cent.), whatever the modifying factors, was 은 superior to that of the 5 -day course ( 55 per cent.).

The effect of the 10-day course of $500 \mathrm{mg}$. four $\stackrel{D}{c}$ times a day (Group C) was clearly superior to that of the 5-day course (Group A). Side-effects in those $\stackrel{5}{+}$ taking the longer courses of treatment (mainly loose $\overrightarrow{\vec{\theta}}$ motions) were of rare occurrence.

In conclusion, it appears that the treatment of nongonococcal urethritis with oxytetracycline at a dose of $250 \mathrm{mg}$. given 6-hourly for 21 days is to be recommended.

\section{Summary}

A trial to assess the value of treatment of nongonococcal urethritis by prolonged dosage of oxytetracycline was carried out at St. Bartholomew's Hospital, London; results from courses of 10 and 21 days were compared with those given by the usual 5-day treatment. The principal assessments were carried out at 4 weeks, 2 months, and 3 months after the completion of treatment. The final cure rates were as follows:

Group A $500 \mathrm{mg}$. three times a day for 5 days; 132 음

followed; 55 per cent. cured.
Group B $250 \mathrm{mg}$. four times a day for 21 days;

200 followed; 87.5 per cent. cured.
Group C $500 \mathrm{mg}$. four times a day for 10 days; 169 followed; 72 per cent. cured. Side-effects were minimal and it is concluded that $\underset{\omega}{N}$ the 21-day course is to be recommended.

My thanks are due to Dr. C. S. Nicol for advice and permission to study the patients under his care, to Dr. $\mathscr{\Phi}$ J. D. J. Parker for giving assistance with the manuscript, to Mrs. R. Bunn for helping to collect the case material and to Miss V. M. Pritchard for secretarial assistance.

\section{References}

CsonkA, G. W. (1959) Brit. F. vener. Dis., 35, 262 DoYLe, J. O., GILI, A. J., and LAIRD, S. M. (1957): Ibid., 33, 100 
FOWLER, W. (1970) Ibid., 46, 464

Holmes, K. K., JoHNSON, D. W., and Floyd, P. M. (1967)

f. Amer. med. Ass., 202, 474.

\section{Efficacité de prescriptions prolongées}

d'oxytétracycline dans le traitement de l'urétrite non gonococcique

SOMMAIRE

A St Bartholomew's Hospital, Londres, on a entrepris un essai pour établir la valeur du traitement de l'urétrite nongonococcique par une posologie prolongée de l'oxytétracycline; les résultats de séries de 10 et 21 jours ont été comparés à ceux obtenus avec le traitemement habituel de 5 jours. Les examens de contrôle furent réalisés, en général, 4 semaines, 2 mois et 3 mois après la fin du traitement. Les taux de guérison complète furent les suivants:

Groupe $A$ : $500 \mathrm{mg}$. trois fois par jour pour 5 jours; 132 cas suivis; 55 pour cent gueris.

Groupe B: $250 \mathrm{mg}$. quatre fois par jour pour 21 jours; 200 suivis, 87,5 pour cent guéris.

Groupe $C: 500 \mathrm{mg}$. quatre fois par jour pour 10 jours; 169 suivis, 72 pour cent guéris.

Les effets secondaires furent minimes et l'on conclut qu'un traitement de 21 jours peut être recommandé. 